\title{
A Brief Analysis on the Improvement of Resistance to Adversity of Adolescents in Growing Dilemma
}

\author{
Jiahui Qin \\ Guangxi University of Science and Technology, Liuzhou 545006, Guangxi, China
}

\begin{abstract}
The mental health of adolescents has been a hot issue in society. This article views the growth predicament of the teenagers from the angle of social work, and helps the teenagers get rid of the growth predicament by improving the resistance to adversity. The resistance to adversity is a very necessary personal quality in the growth and development of the teenagers. From the physical and psychological characteristics of the teenagers in the predicament, it can be learned that the teenagers' behaviors are often manipulated by the emotional factors and tend to produce extreme behaviors. Therefore, it is particularly important to improve the level of stress resistance of adolescents. In real life, when the teenagers are in a difficult situation, good level of resistance can make them better face the setback and calmly seek the solution of the problem, which will help the teenagers accumulate life experience. Therefore, it is of great significance to study how to improve the resistance of teenagers from the angle of social work.
\end{abstract}

Keywords: Stress resistance, Teenagers, Growing predicament.

\section{Introduction}

\subsection{Background}

At present, our country is in the social transformation period, the rapid development of the society and the collision of multi-culture make the stable social order appear turbulence, and then appear many different social ideology, ideology and so on, all influence the contemporary youth subtly. This kind of social change and cultural conflict has a great impact on the behavior mode and thought mode of the immature teenagers. Under this kind of situation, it is very necessary to adjust the psychology of oneself reasonably to face the plural and complicated predicament, which is the only way for the teenagers to socialize.

At present, the related education of adolescents' resistance to adversity is very short. First of all, China's exam-oriented education model still exists, not completely eliminated. Most of the parents and schools pay more attention to the transition rate, which often ignores the ideological and moral education of the teenagers. The lack of students' moral education and the shortage of professional personnel in the anti-adversity education team, as well as the psychological quality of the teenagers can not reach the expected level of the society, so the teenagers can not solve the problems and difficulties effectively in the face of the predicament.

Secondly, parents are busy with their work, which leads to the lack of family education. When the teenagers encounter difficulties, the parents also tend to help their children directly to solve the problem, which makes the teenagers lose the chance of exercising themselves, aggravates the teenagers' dependence on the parents, and makes the teenagers may appear timid, poor psychological endurance, lack of the ability to solve the problem, poor emotional control and so on. Parents can't just think, entrust the children to the school, the school must be able to cultivate young people, and then regardless of their children show indifference. A good family environment is also important for adolescents to improve their resistance to adversity. Finally, the rapid changes and development of the society, the drastic changes of the social structure, the pluralistic ideology and the values of the society all make the teenagers' psychology and the behavior pattern suffer the huge impact, thus to this social adaptability is insufficient.

\subsection{Research Objectives}

Under the background of social pluralism development, teenagers often feel uncomfortable, facing various ideology and values, they can't make correct judgment and reasonable explanation. Therefore, adolescents need to strengthen their judgment and understanding in the process of socialization, and the improvement of the resistance to adversity is very critical for adolescents. Only by improving the resistance to adversity, can they calmly deal with their difficulties in this rapidly changing society, better adapt to the society, and smoothly realize socialization.

\section{Analysis of the Factors Affecting the Improvement of Adolescent Stress Resistance}

\subsection{Service not Equal to Demand}

The factors such as the number of teenagers in the growing dilemma and the lack of channels for help all affect the improvement of their resistance to adversity. Professional social workers are few in our country and the coverage is narrow, so a large proportion of young people cannot get the help of social workers. In our country, social work is still in the initial stage of development, social recognition is not high, the support of the people and the government is insufficient, the service system and developed countries are compared, there is a big gap. Therefore, when helping the young people in the growing predicament, the social workers will also be unable to quickly obtain the multi-personnel cooperation, mobilize the various resources needed, and it will be difficult to deal with the plight of the young people and increase their resistance. 


\subsection{The Family, School and Community do not Pay Enough Attention to Adolescents}

The teenagers will spend nearly one-third of the day in the school. If the school social work is relatively perfect, we can find out the growing predicament that the teenagers encounter in time, so as to help the teenagers solve the problem in time. For example, we can guide them to participate in the anti-adversity activities, improve the social adaptability and the ability to face the predicament. Young people in growing difficulties often lack communication with their families and enclose themselves in their own conscious world. Some families have high expectations for teenagers, which also make them feel more stressed, and then negatively treat their own learning, parents are busy with work and can not notice the changes in their mentality. The relationship among the residents of the community where the teenagers live is weak, and the lack of various activities of the community organization will also affect the behavior pattern and thought of the teenagers.

\subsection{Comprehension of Social Workers against Adversity}

The understanding, understanding and application of the concept of social workers and related staff against adversity, as well as the style and ability of service development, will have a vital impact on helping adolescents out of their growing difficulties and improving their adversity resistance. Because the development of social work in our country is in the beginning stage, the professional skill training and professional education for the staff can not be carried out very well due to the restriction of the conditions, so some social workers can not grasp the concept of anti-adversity well, to promote the youth anti-adversity activities will be carried out more formalism, can not be flexibly used.

\section{Analysis on the Countermeasures Improving the Anti-adverse Force}

\subsection{Seek more Social Support}

According to social support theory, the stronger the social support network an individual can use, the more efficient he will be in dealing with the diverse challenges and difficulties from different environments. Social support theory emphasizes people's feelings in the social environment, emphasizes people's adaptability to the social environment, pays attention to the use of various environmental resources in the surrounding environment system, combines people's development with individual and environmental factors in the environmental adaptability problem, considers that people and various systems in the environment, such as family, community, education, politics, etc., are interactive, thinks through the full and flexible use of social resources can improve the individual's quality of life, and through the formulation of a series of behavior patterns, implementation of corresponding intervention measures, in a certain extent can improve the individual's social life adaptation problem, can stimulate the individual's growth potential and provide full support, can also provide corresponding resources to improve the individual's quality of life. The social support network for young people with growing difficulties is very simple and has little social support. Social workers can enhance the role of social networks in the daily life of adolescents with difficult social network growth by intervening their personal social networks. Especially for those individuals who lack social resources, social workers can expand their social resources and increase their ability to use them by giving them the necessary help. Social support is very important for the young people in the growing predicament, and it is also a direct means of intervention. Besides the government's related policies, the young people must actively seek social support, seek help from relatives, family members and classmates to face the problem together, so as to improve the resistance of the young people to the predicament.

\subsection{Establishing a School-community-family Network}

Schools, communities and families are environmental systems that are closely related to adolescents. Community, school, family are also the social support system of the teenagers in the growing predicament, which helps to establish a caring environment to promote the teenagers' resistance to the predicament. Community is the living community of urban and rural residents, and is the most basic unit of grass-roots governance in China. In the community, social workers can carry out community education and community care to develop a harmonious and friendly atmosphere between neighbors, promote neighborhood communication, help teenagers develop healthy psychology and reduce their chances of getting into growing predicament. Family can provide an environment full of love and security for the teenagers, good parent-child relationship makes the teenagers get more psychological support when facing the predicament and help them get out of the predicament. At school, teenagers can connect with many of their peers to meet their emotional communication needs and gain recognition from their peers. It is easy to construct mutual-aid network of peer groups and promote the formation of good interpersonal relationship. Therefore, the establishment of "school-community-family" linkage network can fully care for and support the young people in growing predicament, excavate the advantages of the young people in growing predicament, provide opportunities for their development and expand growth opportunities. The support of school, community and family are all indispensable. The combination of them can better promote the improvement of the resistance of the teenagers and help the teenagers to get out of the predicament.

\subsection{Improving Personal Characteristics of Adolescents}

Social workers can start with improving the social adaptability of adolescents. Improving social adaptability is the key to enhance the stress resistance of adolescents. The social adaptability of teenagers is influenced by the development of individual. In order to cultivate the youth's social adaptability, we should start with improving the youth's interpersonal communication ability and cooperation consciousness. The cooperative consciousness can make the 
teenagers in the predicament, have the object of talking, deepen the friendship and social cognition through the cooperation, fully explore the self-potential and the resources that can be used around. Second, to cultivate the reasonable expression of empathy and empathy. When others meet, they can help others reduce anxiety and pain, encourage others, and help them get out of trouble. At the same time, it also helps to cultivate the internal quality of the young person and establish a good idea of helping others. Finally, in order to improve the youth problem solving ability, in daily life, everyone will encounter a variety of problems, each of the solutions to problems in various ways. And different ways of solving problems reflect the ability to solve problems, which to some extent reflects an individual's understanding of the problem. It is necessary to cultivate the correct way to deal with the problem and improve their ability to solve the problem, so as to effectively prevent them from deviating from their thinking and behavior, and even to go against the law. Therefore, it is an indispensable means to improve their ability to solve problems.

\section{Summary}

Up to now, there are few methods to combine stress resistance with social work. Most of the research and related work on stress resistance are closely related to psychological education and ideological and moral education. Most of the research in this area is theoretical and not closely related to practice. The society is still insufficient to pay attention to strengthening the resistance of adolescents, and we should pay attention to it. We should often contact the relevant personnel around the teenagers to seek their support and help when carrying out the work of improving the resistance of the teenagers in growing up difficulties, so that they can always reflect on whether some of their words and deeds have had a negative impact on the teenagers and are not conducive to the healthy growth of the teenagers. Finally, the improvement of adolescents' resistance to adversity is of great importance to the growth of adolescents. The puberty troubles and academic difficulties in the growth of adolescents are still the setbacks in the future life. The higher the resistance of adolescents, the more calmly they can deal with the problems. Therefore, the professional working method of social work is very necessary for the intervention of adolescents' resistance to stress. Adolescents are in a very sensitive stage in puberty. If they do not treat and deal with the problem properly, they may produce radical ideas and behaviors.

\section{References}

[1] Yang Tao. Social Work Intervention in Adolescent Growth Dilemma from the Perspective of Advantage - Case Analysis with the Core of Advantage Development[J]. Youth Exploration, 2012.

[2] Wang Sibin. Integrated capacity of social work[M]. China Social Press, 2007.

[3] Shen Zhifei. Interpretation and Cultivation of Adolescent Stress Resistance[J]. Ideological and Theoretical Education, 1.
[4] Gao Jianzhong. Cultivation of Adolescent Stress Resistance[J]. Middle School Politics Reference, 2016, 06: 62-63.

[5] Zhu Hong. Study on Stress Resistance of Adolescents and Its Cultivation of $[\mathrm{J}]$. Global Education Outlook, 2013, 09: 94-99.

[6] Shulia, Tong Min. Case work[M]. Beijing: Higher Education Press, 2015.

[7] Tian Guoxiu, Zhao Jun.Problem Behavior Analysis and Intervention Strategies of High-risk Adolescents: Thinking from the Perspective of Recessive Stress Resistance[J]. Journal of Capital Normal University, Social Science Edition, 2014, 02: 121-126.

[8] Luthar S S, Becker C B. The construct of resilience: A critical evaluation and guidelines for future work $[\mathrm{J}]$. Child Development, 2000, 71(3): 543-562.

[9] Norman E. Resiliency Enhancement: Putting the Strengths Perspective into Social Work Practice[M]. Columbia University Press, 2000.

[10] Ungar, Michael. A Constructionist Discourse on Resilience: Multiple Contexts, Multiple Realities among At-Risk Children and Youth[J]. Youth \& Society, 2004, 35(3): 341-365.

[11] Walsh F. Strengthening Family Resilience[J]. Journal of Marital \& Family Therapy, 1998, 41(2): 252-253.

[12] Maddi, Salvatore R. The Story of Hardiness: Twenty Years of Theorizing, Research, and Practice[J]. Consulting Psychology Journal Practice \& Research, 2002, 54(3): 173-185.

[13] Masten, Ann S. Ordinary magic. Resilience processes in development[J]. American Psychologist, 2001, 56(3): 227.

[14] Greene R R. Resiliency: an integrated approach to practice, policy, and research[M]. NASW Press, 2002. 